American Journal of Pharmacology and Toxicology 2 (2): 39-45, 2007

ISSN 1557-4962

(C) 2007 Science Publications

\title{
In Vitro Studies on the Effect of Phototoxicity of A New Photosensitizer Extracted from Flowers and Aerial Parts of Cichorium pumilum
}

\author{
${ }^{1}$ M-Ali H. Al-Akhras, ${ }^{2}$ Amr Amin, ${ }^{2}$ Karima Mohammad, ${ }^{2}$ Fedae Al-Haddad, ${ }^{2}$ Allaaeldin Hamza \\ ${ }^{1}$ Department of Physics, UAE University \\ ${ }^{2}$ Department of Biology, UAE University
}

\begin{abstract}
New photosensitizers have been extracted from the flowers and aerial parts of the Cichorium Pumilum Jacq (chicory). Chicory grows naturally in local wild areas and is known to cause quick death of only white sheep during its flowering season in autumn. Some of those isolated photosensitizers are yet to be further characterized. Preliminary investigations show a high degradation of isolated photosensitizers under direct sunlight (solar irradiance $450-950 \mathrm{~W} \mathrm{~m}^{-2}$ ). This in vitro study also shows a very high photohemolysis rate at a concentration of $0.95 \mathrm{mg} \mathrm{mL}^{-1}$. The extracted compounds are also found to be temperature dependent. Multiple absorption peaks are also shown for tested extract both in ultraviolet region (at the wavelengths $314,360 \mathrm{~nm}$ ) and in the visible region (at 445,492 and $667 \mathrm{~nm}$ ). Results of the present investigation clearly show the potential of the light- and temperature-dependent extracted compounds as a new member of the photodynamic therapeutics. It is possible therefore that the claimed chicory-induced death of white sheep is simply a direct result of phototoxicity.
\end{abstract}

Keywords: Cichorium pumilum, photobiology, photohemolysis, chicory, photosensitizer

\section{INTRODUCTION}

Natural pigments in some organisms absorb visible and near-ultraviolet light (UV). Natural photosensitizers are present in many organisms including bacteria, fungi, higher plants, protozoa, invertebrates and vertebrates. In northern parts of Jordan and during the flowering season, many incidences of sudden death of white sheeps have been reported immediately after grazing on chicory. Chicory flowers and aerial parts are found to be a source of photosensitizers and therefore their extract is used for this study for the first time. Similar extraction of red plant pigment hypericin (HY) from Hypericum crispum is known to cause severe damage to hemoglobin ${ }^{[1]}$ and therefore developing a photodynamic disease "hypericism" of the grazing animals ${ }^{[2,3]}$. The transient intermediates held responsible for erythrocytes membrane damage include singlet oxygen, superoxide and free radicals.

Photosensitization implies that in the absence of an absorbing pigment, an organism does not react to light of certain wavelengths. Photohemolysis is the release of hemoglobin from erythrocytes induced by lightirradiation. This process is promoted by many photosensitizers such as Photofrin $^{\circledR}$, hypericin, Lutetium Texaphyrin (Lu-Tex) and protoporphyrin
IX ${ }^{[1,4-6]}$. Photohemolysis of RBC in vitro has been studied for many drugs and chemical reagents including synthetic dyes (rose bengal, phloxine $\mathrm{B}^{[7,8]}$, hematoporphyrin, toluidine blue, methylene blue ${ }^{[9]}$, quinolinemethanol anti-malarial compounds ${ }^{[10]}$, butibufen and fluriprofen ${ }^{[11]}$, diflunisa ${ }^{[12]}$, chlorpromazine $^{[13]}, \quad$ griseofulvin $^{[14]}$, carprofen $^{[12]}$, psoralen ${ }^{[15]}$ and metallo-phthalocyanine sulfonates ${ }^{[16]}$. A comparative study for the quinolinemethanol antimalarial compounds showed a good correlation between the in vitro photohemolysis rate and the minimum effective dose of erythema (an abnormal redness of the skin) in mice ${ }^{[10]}$. Some of these drugs are found to be sensitive to light. Root aqueous extracts of Cichorium intybus have been reported as a lightsensitive plant remedy for malaria with Lactucin and Lactucopicrin representing the anti-malarial compounds ${ }^{[17]}$. Light sensitivity of the root extract has been confirmed by other researchers ${ }^{[18,19]}$. In addition, an antibacterial activity has been reported for extracts of roots and aerial parts of Cichorium pumilum ${ }^{[20]}$. Photosensitization implies that, in the absence of an absorbing pigment, an organism does not react to light of certain wavelengths. Sensitization of RBC photohemolysis in vitro has also been used as an indicator of phototoxicity which is a major side-effect

Corresponding Author: $\quad$ M-Ali Al-Akhras, Department of Physics, UAE University, Al-Ain, P.O. Box 17551, UAE, Tel: 971-3-7064760, Fax: 971-3-7671291 
of most phototherapeutic drugs ${ }^{[21]}$. Hemolysis is defined as a released of hemoglobin from red blood cells (RBC) into the surrounding medium causing serious diseases such as babesiosis. In folk medicine herbal remedies have been and still are traditionally used ${ }^{[17,20]}$. In India chicory plant is cultivated and is commonly used to treat diarrhea, enlargement of the spleen, fever, vomiting and as a tonic reagent. Ancient Egyptians, Greeks and Romans used chicory to treat liver diseases. Chicory root is said to be a folk remedy for treating stomach $\mathrm{ache}^{[22]}$, an aperitif and an antiinflammatory ${ }^{[23]}$, antioxidant activity ${ }^{[24]}$, healing kidney stone $^{[25]}$, restoring or preventing immunotoxicity ${ }^{[26]}$ and relief from gout ${ }^{[27]}$, Inhibition of Ehrlich ascites carcinoma and enlargement of spleen, gout and rheumatism ${ }^{[28]}$. Chicory root extracts are very rich in inulin and oligofructose. These extracts are found to be significantly inhibited the growth of various kinds of cancerous tumours in rats ${ }^{[27]}$. Chicory seeds are also known for its medicinal benefits. Chicory seeds are usually prescribed for week spleens and represent the main ingredient of "Jigrine", a commercial Indian product which is commonly used to treat of various liver diseases ${ }^{[29]}$. Aqueous root extract is said to heal breast and lung tumors ${ }^{[30]}$. Chicory leaves and roots also produce bitter sesquiterpene lactones which is used as an appetizer and to have diuretic properties ${ }^{[20,31]}$. Chicory extract is also known as an antioxidant and may also have anti-inflammatory properties ${ }^{[32]}$.

A comprehensive evaluation of the relationship between human phototoxicity and RBC photohemolysis has not yet been reported. In vitro studies of RBC photohemolysis are based on post-irradiation or delayed photohemolysis (DPH), where a suspension of RBCs along with aqueous extract is exposed to direct sunlight dose, followed by measurements of the photohemolysis rate in the dark. A typical photohemolysis curve has a sigmoidal shape.

A new kinetics model for photohemolysis was reported in which sensitized photohemolysis is attributed to cooperative photochemical and thermal processes $^{[1,4-6]}$. The present investigation reports new DPH results fitted to Gompertz function module ${ }^{[5,6]}$. The Gompertz function is defined as:

$H=H_{0} e^{-a e^{-b t}}$

where:

$H$ is the percentage of hemolysis during the lysis time $t$ (the time measured from start of rupturing the RBCs at dark incubation).

$H_{0}$ is the initial maximum number of cells, normalized to one. $a$ is a fractional hemolysis ratio and $b$ is the rate of fractional hemolysis change.

To our knowledge, there are no prior reports discussed the phototoxicity or photo-allergy of the extract tested here. The objectives of this study are to identify and characterize the extract's effective compounds (which are sensitive to sunlight) and to examine their phototoxicity in vitro. In this study, the kinetics of red blood cell photohemolysis sensitized by tested compounds will also be investigated.

\section{MATERIALS AND METHODS}

Plant extraction: Flowers and top parts of chicory were collected from local wild areas in northern Jordan during end of May 2006. Collected plat parts were washed with running water and were then air dried in a dark room.

Chicory flowers and aerial parts were extracted using a microwave-assisted extraction method as described in $^{[33]}$. In this method, extraction is based on the selective heating of the matrix that contains the target extract when the matrix is immersed in a solvent such as ethanol and water, which is transparent to the microwaves. This solvent, allows for selective heating of particular components within the materials being treated, without using excessive energy. The dried flower and aerial parts of chicory were cut into small pieces and grinded for short periods of time to get powder mixtures. Hundred grams of dried powder were mixed in $1000 \mathrm{~mL}$ of $50 \%$ ethanol and $50 \%$ water. Every $10 \mathrm{gm}$ of powder mixed with $100 \mathrm{~mL}$ of $50 \%$ ethanol in $250-\mathrm{mL}$ conical flask. Mixtures were then irradiated with microwave for two minutes. The output power of the microwave oven is $300 \mathrm{~W}$. The suspension was irradiated for 25 seconds with power on to give the desired temperature of about $80^{\circ} \mathrm{C}$ and then disconnect immediately and re-irradiate for 5 second with power on for heating and then for 10 minutes with power off for cooling. The process was repeated three times and the herb kept over night inside the refrigerator. The extract was finally filtered through gauze and evaporated under vacuum at $40^{\circ} \mathrm{C}$ using a rotary evaporator. The extraction was dissolved in phosphate buffered saline (PBS, P4417), purchased from Sigma/USA (P4417 Sigma, USA).

Solar irradiance: A Pyranometer instrument (LI-1000 LI-COR/USA) was used to measure the solar irradiance. The calibrated radiometer was mounted horizontally facing upwards. 


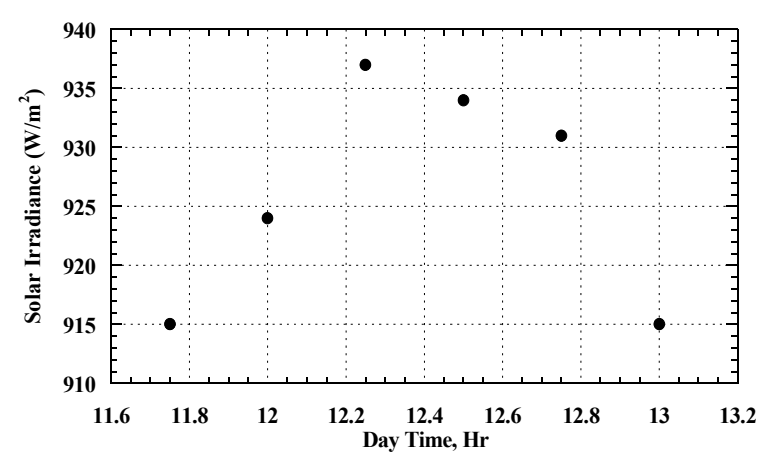

Fig. 1: Global solar irradiance measurements during the summer at UAE University $\left(24^{0} 11^{\prime} 50.92^{\prime}{ }^{\prime} \mathrm{N}\right.$ and $\left.55^{\circ} 41^{\prime} 03.04^{\prime}{ }^{\prime} \mathrm{E}\right)$

One of the measurements for the global solar irradiance during the summer is shown in Fig. 1 with an accuracy of about 3\%. Present experiments were conducted at UAE University $\left(24^{0} 11^{\prime} 50.92^{\prime}{ }^{\prime} \mathrm{N}\right.$ and $\left.55^{\circ} 41^{\prime} 03.04^{\prime}{ }^{\prime} \mathrm{E}\right)$.

Sample preparation: Fresh human blood samples were donated by healthy volunteers. RBCs were isolated by centrifugation at $3000 \mathrm{xg}$ for $10 \mathrm{~min}$. at $4^{\circ} \mathrm{C}$. RBCs were mixed with diluted extract in addition to other ingredients as detailed later. Blood samples were mixed with phosphate buffered saline (PBS), $(\mathrm{pH}=7.4)$ and different dilutions of chicory's extract. All samples that contain extract are prepared in dark room. The kinetics of the fractional damage of the irradiated sample was followed spectrophotometrically by measuring the optical density as a function of time.

Spectrophotometry: Samples were incubated for 10 min at $37^{\circ} \mathrm{C}$ with or without light followed by the spectrophotometric measurements of the optical density at a fixed wavelength $(650 \mathrm{~nm})$. The optical densities were measured as a function of lysis time. The measurements were taken in a dark room and at room temperature.

\section{RESULTS AND DISCUSSION}

Figure 2 shows the spectrum of the extracted compounds from the flower and aerial part of Cichorium Pumilum. Strong absorption bands at 314 $\mathrm{nm}, 360 \mathrm{~nm}$ in UV region and $445 \mathrm{~nm}, 492 \mathrm{~nm}$ and 667 $\mathrm{nm}$ in the VIS region are observed. The extracted materials are found to be strongly dependent on temperature and very strongly dependent on solar intensity with a maximum effect around noon time (Fig. 1). Figure 3 shows the effect of light dose $950 \mathrm{~W} \mathrm{~m}^{-2}$ at $43^{\circ} \mathrm{C}$ with fixed extract concentration at $0.95 \mathrm{mg} \mathrm{mL}^{-1}$. Typical hemolysis curves with higher steepness and higher $t_{50}$ (the time required to rupture $50 \%$ of the total

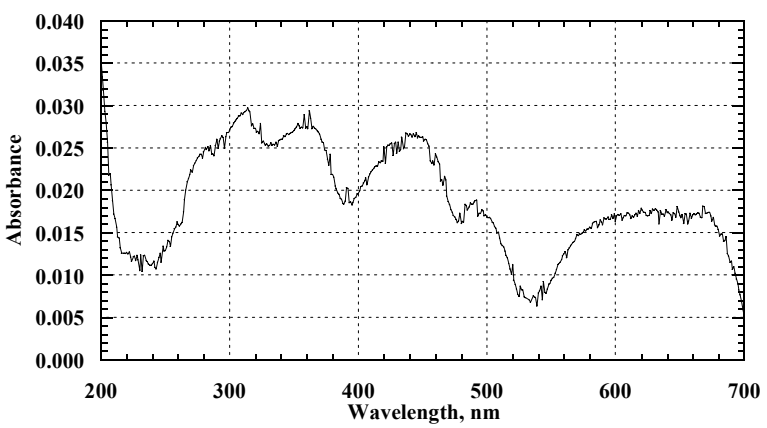

Fig. 2: Flower and aerial part spectrum with absorbance peaks at 314 $\mathrm{nm}, 360 \mathrm{~nm}$ in UV region and $445 \mathrm{~nm}, 492 \mathrm{~nm}$ and $667 \mathrm{~nm}$ in the VIS region



Fig. 3: Effect of light doses $950 \mathrm{~W} \mathrm{~m} \mathrm{~m}^{-2}$ at $43^{\circ} \mathrm{C}$ with fixed extract's concentration $0.95 \mathrm{mg} \mathrm{mL}^{-1}$, the points are the experimental data points and the solid lines of $\mathrm{A}, \mathrm{B}, \mathrm{C}, \mathrm{D}$ and $\mathrm{E}$ are the theoretical fitting to Eq. 1: C1, first control with $\mathrm{RBC}$ only; $\mathrm{C} 2$, second control RBC plus extraction $\left(0.95 \mathrm{mg} \mathrm{mL}^{-1}\right)$ with no light; A) $2 \mathrm{~min}$. Light irradiation B) $4 \mathrm{~min}$. Light irradiation C) $6 \mathrm{~min}$. Light irradiation D) $8 \mathrm{~min}$. Light irradiation and E) $10 \mathrm{~min}$. Light irradiation

RBCs when $H=0.5 H_{0}$ ) are noticed at lower concentration. All data points are normalized to one. The sample of control line $\mathrm{C} 1$ contained RBCs suspended in PBS showed no effect of temperature on $\mathrm{RBC}$. Line $\mathrm{C} 2$ with extract concentration at $0.95 \mathrm{mg}$ $\mathrm{mL}^{-1}$ served as control for the samples A, B, C, D and $\mathrm{E}$. The slight decrease in $\mathrm{C} 2$ is due to temperature while the light effect can be seen clearly where higher irradiation time accelerates hemolysis much faster compared to control (C2). The solid lines of A, B, C, D and $\mathrm{E}$ are the theoretical fitting to Eq. 1 while the 


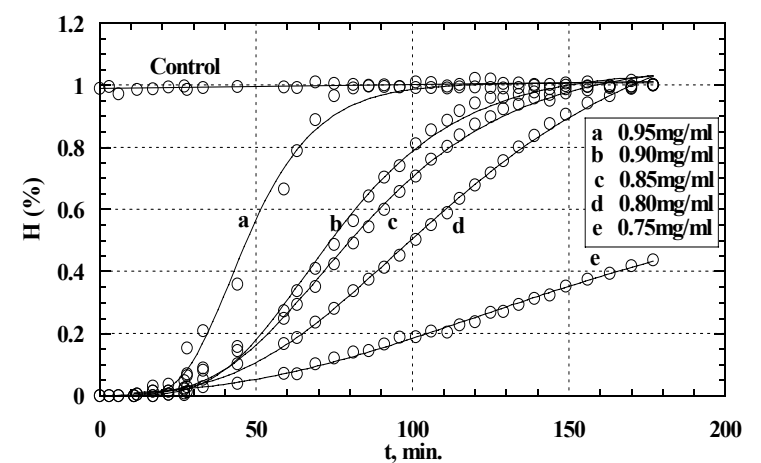

Fig. 4: Effect of room temperature on RBC sensitized by different concentrations of flower and aerial part extracts, where $\mathrm{C}$ is the control contained $\mathrm{RBC}$ only, a) $0.95 \mathrm{mg} \mathrm{mL}^{-1}$, b) $0.90 \mathrm{mg}$ $\mathrm{mL}^{-1}$, c) $0.85 \mathrm{mg} \mathrm{mL}^{-1}$ d) $0.80 \mathrm{mg} \mathrm{mL}^{-1}$ and e) $0.75 \mathrm{mg} \mathrm{mL}^{-1}$. The points are the experimental data points and the solid lines are the theoretical fitting to Eq. 1

circles are the experimental data pints. The time required rupturing $50 \%$ of the cells $t_{50}$ and the fitted parameters " $a$ " and " $b$ " are summarized in Table 1, Group I. The rate of fractional hemolysis " $b$ " increases with the decrease of the hemolytic process and can be represented by $t_{50}$. The faster the hemolytic process goes, the greater the $t_{50}$ gets and the slower the hemolysis becomes the lower $t_{50}$. The fractional hemolysis ratio " $a$ " decreases at lower irradiation time and increases at higher irradiation time. Group II shows the increases in $t_{50}$ with increasing " $a$ " and " $b$ " while the $t_{50}$ is increasing with decreasing the concentration.

Figure 4 shows the effect of room temperature on RBC sensitized by different concentration of the extracted compounds. The line $\mathrm{C}$ is the control contained RBC only whereas the other lines represented by circles are the samples with different extract's concentrations $(0.95,0.90,0.85,0.80$ and $0.75 \mathrm{mg}$ $\mathrm{mL}^{-1}$ ). Solid lines are the theoretical fitting to Eq. 1 . Samples with higher concentration have higher hemolysis rate in shorter time. The theoretical parameters are summarized in Table 2 (Group I). The data shown in Group II are for the samples exposed to $40^{\circ} \mathrm{C}$. The ratio " $a$ " and the $t_{50}$ of group I are higher than that of Group II. The rate of fractional hemolysis " $b$ " is very high at higher concentration $0.95 \mathrm{mg} \mathrm{mL}^{-1}$ in both groups.

The present study reports a novel photohemolysis effect flowers and aerial parts extracts of Cichorium Pumilum. This extract is found to be viscous, dark pasty, soluble in water and is sensitive to both temperature and light. Unlike photo allergy, phototoxicity is rapidly developed after the initial light exposure, characterized by systemic responses and is accompanied by many histopathologic lesions. The adverse reactions induced by phototoxicity such as photohemolysis (red cell membrane damage) and photoirritation (acute skin irritation and edema in guinea-pig and mice) are mainly oxygen-dependent reactions. Both in vivo and in vitro studies have related this phototoxicity to the generation of reactive oxygen species (ROS) such as hydrogen peroxides and hydroxyl radicals. Accumulation of ROS results in oxidative stress which induces oxidative modifications of biomolecules of membranes such as lipids, DNA and proteins $^{[34,35]}$. However, photosensitivity reactions can have beneficial effects as in photodynamic therapy (PDT) to treat malignant tumors. PDT employs the interaction of a photosensitizer with light of the appropriate wavelength in the presence of molecular oxygen ${ }^{[36]}$.

The present results report a multi-step photohemolysis of RBCs and the associated membrane damage. First, the fractional hemolysis occurred in the presence of extracted compounds and temperature. Then, the fractional hemolysis occurred in the presence of extracted compounds plus temperature and light. The final step is rather complex process where both temperature and light are required in addition to the extracted compounds (Table 1). The theoretical fitting of all three steps predicts that the value of $t_{50}$ is much lower on the light dose while the fractional photohemolysis rate is higher at higher temperature exposure (Table 1 and 2). These predictions were experimentally confirmed in prior studies for Sodium Hypericin (HY-Na) and Photofrin (PF $)^{[1]}$, protoporphyrin $\mathrm{IX}^{[19]}$ and for osmotic fragility ${ }^{[20]}$. The theoretical modeling is further supported by good fit of calculated lysis curves to the data in Table 1 and 2 . Most of the prior studies were limited to roots and leaves extracts of the plant. Phototoxicity of the plant extracts received very little attention and is still poorly understood.

In general the values of $t_{50}$, "a" and " $b "$ should depend on the effect of temperature and sensitizer concentration, the absorbed light dose and on the physical distribution of sensitizer molecules at membrane targets. The apparent anomaly was attributed in prior work to partitioning of the dye between the aqueous phase and RBCs.

The colloid osmotic kinetics model of Pooler proposes a specific mechanism for the thermal stage of hemolysis based on changes of membrane permeability to sodium and potassium ions ${ }^{[37]}$. Further investigation based on osmotic fragility measurements has led to an osmolarity-dependent fractional lysis that simulated lysis curves. The application of this model for 
Am. J. Pharm. \& Toxicol., 2 (2): 39-45, 2007

Table 1: Effect of light doses $915-950 \mathrm{~W} \mathrm{~m}^{-2}$ at $40-43^{\circ} \mathrm{C}$ with fixed extract's concentration $\left(0.95 \mathrm{mg} \mathrm{mL}^{-1}\right.$, Group I) and fixed irradiation time ( 5 min, Group II), the theoretical parameters " $a$ " and " $b$ " are the fitting data to Eq. 1 for the solid lines of A, B, C, D and E of Fig. 3

\begin{tabular}{llllll}
\hline Sample & Irradiation time $(\mathrm{min})$ & $t_{50}(\mathrm{~min})$ & $a^{*}$ & $b^{\#}\left(\mathrm{~min}^{-1}\right)$ & \\
\hline Group I & & & & & \\
$\left(0.95 \mathrm{mg} \mathrm{mL}{ }^{-1}\right)$ & 2 & N.A & $14.549 \pm 0.956$ & $0.136 \pm 0.003$ & $0.026 \pm 0.001$ \\
& 4 & N.A & $3.530 \pm 0.098$ & $0.021 \pm 0.001$ & 0.997 \\
& 6 & N.A & $2.809 \pm 0.095$ & $0.021 \pm 0.001$ & 0.991 \\
& 8 & 59 & $3.035 \pm 0.083$ & $0.020 \pm 0.001$ & 0.994 \\
\hline Group II & 10 & 22 & $3.195 \pm 0.087$ & & \\
$0.95 \mathrm{mg} \mathrm{mL}^{-1}$ & 5 & & & & \\
$0.75 \mathrm{mg} \mathrm{mL}^{-1}$ & 5 & 12 & $3.226 \pm 0.149$ & $0.269 \pm 0.008$ & 0.998 \\
$0.65 \mathrm{mg} \mathrm{mL}^{-1}$ & 5 & 35 & $2.838 \pm 0.073$ & $0.048 \pm 0.003$ & 0.997 \\
\hline
\end{tabular}

Results are expressed as means $\pm \mathrm{SD}$

*Experimental values obtained from data curves at $\mathrm{H}=0.5 \mathrm{H} 0$

\#Theoretical values calculated from Eq. 1

\$Correlation coefficient

Table 2: Effect of temperatures on RBCs with different extract's concentrations in dark. Group I was exposed to room temperature whereas Group II was exposed to $40^{\circ} \mathrm{C}$ for $10 \mathrm{~min}$

\begin{tabular}{llllll}
\hline Sample & $\mathrm{C}(\mathrm{mg} / \mathrm{mL})$ & $t_{50}(\mathrm{~min})$ & $a^{*}$ & $b^{\#}\left(\mathrm{~min}^{-1}\right)$ & $0.067 \pm 0.004$ \\
\hline Group I & 0.95 & 47 & $16.039 \pm 2.753$ & $0.036 \pm 0.002$ & 0.996 \\
& 0.90 & 74 & $10.849 \pm 1.146$ & $0.030 \pm 0.001$ & 0.998 \\
& 0.85 & 80 & $8.366 \pm 0.585$ & $0.020 \pm 0.001$ & 0.999 \\
& 0.80 & N.A & $6.691 \pm 0.269$ & $0.013 \pm 0.001$ & 0.999 \\
\hline Group II & 0.75 & 4 & $5.023 \pm 0.225$ & $0.342 \pm 0.026$ & 0.990 \\
& 0.95 & 30 & $2.875 \pm 0.419$ & $0.053 \pm 0.002$ & 0.998 \\
& 0.90 & 43 & $3.396 \pm 0.133$ & $0.034 \pm 0.001$ & 0.997 \\
& 0.85 & 52 & $3.472 \pm 0.153$ & $0.026 \pm 0.002$ & 0.995 \\
& 0.80 & 60 & $3.448 \pm 0.174$ & $0.019 \pm 0.001$ & 0.998 \\
\hline
\end{tabular}

Results are expressed as means \pm SD

${ }^{*}$ Experimental values obtained from data curves at $H=0.5 H_{0}$

${ }^{*}$ Theoretical values calculated from Eq. 1

${ }^{\$}$ Correlation coefficient

photohemolysis assumes that the only effect of light is to increase the membrane cation-permeability and that the osmotic properties of the membranes are not altered from untreated (control) cells. The present findings and that of Pooler are complementary. Thus, Cichorium Pumilum extract was much more photosensitizing than $\mathrm{PF}$ and Hy-Na owing to its strong absorption bands in the UV and VIS regions (Fig. 2).

These empirical parameters should be useful for comparing the relative photohemolysis efficiency of different compounds and for correlating in vivo/in vitro photohemolysis with photosensitization. The results might provide information applicable to the broader aspects of membrane photosensitization such as power dependency on drug concentration and irradiation time and temperature and the key kinetics parameters represented by mathematical modeling (Table 1 and 2). The present results may also lead to a new photodynamic drugs and/or a light-sensitive herb remedy for many diseases. Among the novel aspects of this work, is providing a qualitative and quantitative modeling analysis of photohemolysis kinetics of an economically important plant. Several studies of chicory effects on sheep ended up with contradictory results. Guldberg et al., concluded that chicory had the largest impact on the establishment of the parasites in ram lambs due to gazing on Cichorium Intybus for six weeks $^{[38]}$. On the other hand, chicory has been reported to reduce the number of infective parasite larvae available for ingestion by grazing sheep compared with ryegrass $^{[39]}$. Other report has shown that when grazed by sheep and other ruminants, chicory may reduce internal parasite intensities ${ }^{[40]}$. In other in vitro study, it has been shown that chicory had no effect on hatching and development of nematode eggs and larvae, but did reduce the number of lungworm larvae developing to the L3 stage ${ }^{[41]}$.

The new results with chicory extraction fitted to Gompertz function show that the delayed photohemolysis rate parameters " $b$ " is similar to previous finding ${ }^{[1,5,6]}$. This model extends the colloidosmotic model ${ }^{[37]}$ by attributing membrane rupture to 
the combined effects of cell swelling induced by damage to the anion transport protein and thermallyactivated photochemical damage to structural membrane proteins. The importance of the latter effect probably depends on the specific photosensitiser and the reaction conditions.

\section{CONCLUSION}

For the first time the observations reported in this study suggest the hypothesis that the extractions from the flower and top part of Cichorium Pumilum are light and temperature dependent. Therefore, the chicory extracts pigments are could be the responsible for the photodynamic disease of grazing animals.

The most important conclusion derived from the present study is that photohemolysis requires thermal activation of photochemical damage. A similar cooperative process was proposed for psoralen by Potapenko et $a l^{[42]}$. The rate of hemolysis photosensitized by hematoporphyrin derivative HPD was greatly accelerated by post-irradiation heating to $50^{\circ} \mathrm{C}$, which is consistent with this mechanism ${ }^{[43]}$. Furthermore, these results showed that the mathematical analysis technique adapts to study the effects of light and thermal activations on the photohemolysis process at different conditions as a best-fit model with minimum parameters and minimum errors.

Further in vivo/vitro studies are needed to assess the activity of chicory extracts as potential tumor inhibitor.

\section{ACKNOWLEDGMENTS}

This work was funded by the Scientific Research Council of UAE University, grant \# 08-02-2-11/06 and partially by Higher Council for Science and Technology/Jordan, grant \# 62/2000.

\section{REFERENCES}

1. Al-Akhras, M. and L. Grossweiner, 1996. Sensitization of photohemolysis by hypericin and Photofrin $^{\circledR}$. J. Photochem. Photobiol. B Biol., 34: 169-175.

2. Giese, A., 1971. Photosensitization by Natural Pigments. In Photophysiology. (Giese AC,Ed) Academic press, New York, 6: 77-129

3. Blum, H. 1941. Photodynamic Action and Diseases Caused by Light. Reinhold Publishing Corporation.

4. Bilgin, M. Al-Akhras, M-Ali, M. Khalilli, H. Hemmati and L.I. Grossweiner.2000. Photosensitization of red blood cell hemolysis by lutetium texaphyrin (Lu-Tex); Photochem. Photobiol., 72: 121-127.
5. Al-Akhras, M., 2006. A new application of gompertz function in photohemolysis: The effect of temperature on red blood cell hemolysis photosensitized by protoporphyrin IX. Medical \& Biological Eng \& Computing., 44: 703-710.

6. Al-Akhras, M., 2006. Effect of additives and photosensitive drugs on osmotic fragility. Int. J. Sci. Res. 16: 363-369.

7. Cook, J. and H. Blum, 1959. Dose relationships and oxygen dependence in ultraviolet and photodynamic hemolysis. J. Cell. Comp. Physiol., 53: 41-60.

8. Valenzeno, D. and J. Pooler, 1982. Cell membrane photomodificatin: relative effectieness of halogenated oresceins for photohemolysis. Photochim. Photobiol., 35: 343-350.

9. Jauarranz, A.A. Villanueva, V. Diaz and L. Rodriguez-Borlado et al., 1993. Induced photohemolysis of rabbit red blood cells by several photosensitizers. Anticancer Drugs, 4: 501-504.

10. Epling, G. and M. Sibley, 1987. Photosensitized lysis of red blood cells by phototoxic antimalarial compounds. Photochem. Photobiol., 46: 39-43.

11. Castell, J., M. Gomez-Lechon, M. Miranda and I. Morera, 1992. Phototoxicity of non-steroidal antiinflammatory drugs: In vitro testing of the photoproducts of butibufen and flurbiprofen. J. Photochem. Photobiol. B: Biol., 13: 71-81.

12. De Guidi, G., R. Chillemi, L. Costanzo, S. Giuffrida and G. Condorelli, 1993. Molecular mechanism of drug photosensitization 4. Photohemolysis sensitized by carprofen. J. Photochem. Photobiol. B: Biol., 17: 239-246.

13. Kochevar, I. and J. Hom, 1983. Photoproducts of chlorpromazine which cause red blood cell lysis. Photochem. Photobiol., 37: 163-168.

14. Fujita, H., N. Inukai and I. Matsuo, 1993. In vitro photosensitized lysis of red blood cells by an antifungal drug griseofulvin. J. Photochem. Photobiol. B: Biol., 17: 77-80.

15. Potapenko, A., S. Saparov, M. Agamalieva, E. Lysenko, L. Bezdetnaya and V. Sukhorukov, 1993. $\mathrm{Fe}^{2+}$ ions and reduced glutathione - chemical activators of psoralen- sensitized photohaemolysis. J. Photochem. Photobiol. B: Biol., 17: 69-75.

16. Sonoda, M., C. Krishna and P. Riesz, 1987. The role of singlet oxygen in the photohemolysis of red blood cells sensitized by phthalocyanine sulfinates. Photochem. Photobiol., 46: 625-631.

17. Biscoff, T., C. Kelley, Y. Karchesy, M. Laurantos, P. Nguyen-Dinh and A. Arefi, 2004. Antimalarial activity of lactucin and lactucopicrin: Sesquiterpene lactones isolated from Cichorium intybus L. J. Ethnopharmacol., 95: 455-457. 
18. Boeuf, G., B. Legrand and S. Rambour, 1999. Influence of light conditions on development, apoplastic peroxidase activities and peroxidase isoenzymes in chicory root explants. Physiol. Plant., 106: 331-336.

19. Frey, U., J. Claude, S. Crelier and M. Juillert, 2002. UV degradation of sesquiterpene lactones in Chicory extract kinetics and identification of reaction products by HPLC-MS. Chmia, 56: 292293.

20. Petrovic, J., A. Stanojkovic, Lj. Comic and S. Curcic, 2004. Antibacterial activity of Cichorium intybus. Fitoterapia, 75: 737-739.

21. David, C.S., C. Briggs, C. Whitehurst, C.D. Betts, K.J. O'Flynn, N.W. Clarke and J.V. Moore, 2004. Photodynamic therapy for superficial bladder cancer. Expert Review of Anticancer Therapy, 4: 283-288.

22. Sezik, E., E. Yesilada, H. Shadidoyatov, Z. Kulivey, A. Nigmatullaev, H. Aripov, Y. Takaishi, Y. Takeda and G. Honda, 2004. Folk medicine in Uzbekistan I. Toshkent, Djizzax and Samarqand provinces. J. Ethnopharmacol., 92: 197-207.

23. Guarrera, P., 2003. Food medicine and minor nourishment in the folk traditions of Central Italy (Marche, Abruzzo and Latium). Fitoterapia, 74: 515-544.

24. Ivanova, D., D. Gerova, T. Chervenkov and T. Yankova, 2005. Polyphenols and antioxidant capacity of Bulgarian medicinal plants. J. Ethnopharmacol., 96: 145-150.

25. Pieroni, A., H. Muenz, M. Akbulut, K. Hüsnü, C. Başer and C. Durmuşkahya, 2005. Traditional phytotherapy and trans-cultural pharmacy among Turkish migrants living in Cologne, Germany. J. Ethnopharmacol., 102: 69-88.

26. Kim, J., W. Woo, K. Jeon, N. An and J. Park, 2002. Effects of the ethanol extract Cichorium intybus on the immunotoxicity by ethanol in mice. Int. Immunopharmacol., 2: 733-44

27. Kaur, N. and A. Gupta, 2002. Applications of inulin and oligofructose in health and nutrition. J. Biosci., 27: 703-714.

28. Hazra, B., R. Sarkar, S. Bhattacharyya and P. Roy, 2002. Tumour inhibitory activity of chicory root extract against Ehrlich ascites carcinoma in mice. Fitoterapia, 73: 730-733.

29. Bahar Ahmed, Tawfeq A. Al-Howiring and A.B. Siddiqui, 2003. Antihepatotoxic activity of seeds of Cichorium intybus. J. Ethnopharmacol., 87: 237240.

30. http://www.herbnet.com/Herb\%20Uses_C.htm

31. Wanda, K. and Z. Klaudia, 2001. Guaianolides from Cichorium intybus and structure revision of Cichorium sesquiterpene lactones. Phytochemistry, 57: 523-527.
32. Archives of Pharmacal Research, Oct. 2001, pp: 431-436 and Natural Medicines Comprehensive Database, (www.naturaldatabase.com).

33. Pan, X., G. Niu and H. Liu, 2003. Microwaveassisted extraction of tea polyphenols and tea caffeine from green tea leaves. Chem. Eng. Process., 42: 129-133.

34. Djordjevic, V.B., 2004. Free radicals in cell biology. Int. Rev. Cytol., 237:57-89.

35. Sorg, O., 2004. Oxidative stress: A theoretical model or a biological reality. C. R. Biologies, 327:649-662.

36. Henderson, B.W. and T. Dougherty, 1992. How does photodynamic therapy work? Photochem. Photobiol., 55: 145-157.

37. Pooler, J. 1985. The kinetics of colloid osmotic hemolysis. II. Photohemolysis. biochimica et biophysica acta, 812: 199-205.

38. Guldberg, C., L.T. Jørgensen, H. Mejer and S.M. Thamsborg, 2002. Department of Animal Science and Animal Health; b/ Danish Centre for Experimental Parasitology, Royal Veterinary and Agricultural University, Copenhagen. http:// www. dsp. kvl. dk/DSP abstracts 2002. htm

39. Marley, C.L., R. Cook, J. Barrett, R. Keatinge and N.H. Lampkin, 2006. The effects of birdsfoot trefoil (Lotus corniculatus) and chicory (Cichorium pumilum) when compared with perennial ryegrass (Lolium perenne) on ovine gastrointestinal parasite development, survival and migration. Vet. Parasitol., 138: 280-290.

40. Marley, C.L., Cook, R., Keatinge, R., Barrett, J., Lampkin, N.H., 2003. The effect of birdsfoot trefoil (Lotus corniculatus) and chicory (Cichorium Pumilum) on parasite intensities and perfor-mance of lambs naturally-infected with helminth parasites. Vet. Parasitol. 112, 147-155.

41. Schreurs, N.M., A.L. Molan, N. Lopez-Villalobos, T.N. Barry and W.C. McNabb, 2002. Effects of grazing undrenched weaner deer on chicory or perennial ryegrass/white clover pasture on the viability of gastrointestinal nematodes and lungworms. Vet. Rec., 151: 348.

42. Potapenko, A., S. Wunderlich, F. Pliquett, L. Bezdetnaya and V. Sukhorukov, 1986. Photosensitized modification of erythrocyte membranes induced by furocoumarins. Photobiochem. Photobiophys., 10: 175-180.

43. Beaton, R., 1995. Alteration in erythrocyte organization induced by the photosensitizer hematoporphyrin derivation. Photochem. Photobiol., 62: 353-355. 